\title{
Hypothalamic glucose sensing: making ends meet
}

\author{
Vanessa H. Routh ${ }^{1 *}$, Lihong Hao ${ }^{1,2}$, Ammy M. Santiago ${ }^{1,2}$, Zhenyu Sheng ${ }^{1}$ and Chunxue Zhou ${ }^{1,2}$ \\ ${ }^{1}$ Department of Pharmacology and Physiology, New Jersey Medical School, Rutgers University, Newark, NJ, USA \\ ${ }^{2}$ Department of Pharmacology and Physiology and Graduate School of the Biomedical Sciences, New Jersey Medical School, Rutgers University, Newark, NJ, USA
}

Edited by:

Arshad M. Khan, University of Texas at EI Paso, USA

\section{Reviewed by:}

Kevin W. Williams, The University of

Texas Southwestern Medical

Center, USA

Owen Chan, Yale University, USA

William Colmers, University of

Alberta, Canada

\section{*Correspondence:}

Vanessa H. Routh, Department of Pharmacology and Physiology, New Jersey Medical School, Rutgers University, Medical Science Building, 185 S. Orange Ave., Newark, NJ 07103, USA

e-mail: routhvh@njms.rutgers.edu
The neuroendocrine system governs essential survival and homeostatic functions. For example, growth is needed for development, thermoregulation maintains optimal core temperature in a changing environment, and reproduction ensures species survival. Stress and immune responses enable an organism to overcome external and internal threats while the circadian system regulates arousal and sleep such that vegetative and active functions do not overlap. All of these functions require a significant portion of the body's energy. As the integrator of the neuroendocrine system, the hypothalamus carefully assesses the energy status of the body in order to appropriately partition resources to provide for each system without compromising the others. While doing so the hypothalamus must ensure that adequate glucose levels are preserved for brain function since glucose is the primary fuel of the brain. To this end, the hypothalamus contains specialized glucose sensing neurons which are scattered throughout the nuclei controlling distinct neuroendocrine functions. We hypothesize that these neurons play a key role in enabling the hypothalamus to partition energy to meet these peripheral survival needs without endangering the brain's glucose supply. This review will first describe the varied mechanisms underlying glucose sensing in neurons within discrete hypothalamic nuclei. We will then evaluate the way in which peripheral energy status regulates glucose sensitivity. For example, during energy deficit such as fasting specific hypothalamic glucose sensing neurons become sensitized to decreased glucose. This increases the gain of the information relay when glucose availability is a greater concern for the brain. Finally, changes in glucose sensitivity under pathological conditions (e.g., recurrent insulin-hypoglycemia, diabetes) will be addressed. The overall goal of this review is to place glucose sensing neurons within the context of hypothalamic control of neuroendocrine function.

Keywords: glucose-excited neurons, glucose-inhibited neurons, hypoglycemia, starvation, glucose homeostasis, orexin, agouti-related peptide, nitric oxide

\section{INTRODUCTION}

Our neuroendocrine systems maintain homeostasis against changing internal and external stressors. In order to do this, it is necessary to carefully partition fuel to each system which requires energy without compromising a constant brain glucose supply. The primary responsibility for this fuel partitioning falls upon the hypothalamus. The hypothalamus integrates autonomic responses and endocrine function with behaviors, especially those concerned with the homeostatic requirements of everyday life. There are five basic physiological needs which are governed by the hypothalamus. These are the regulation of blood pressure and electrolyte composition, body temperature, energy metabolism, reproduction, and the emergency response to stress. In order to do this, the hypothalamus receives sensory information from the entire body. This input includes visceral sensory afferents as well as circulating hormones. The hypothalamus possesses internal sensory neurons which detect changes in local temperature, osmolality, electrolytes and nutrients such as glucose and free fatty acids. The hypothalamus then compares the information from this input with biological set points and adjusts an array of autonomic, endocrine and behavioral responses in order to maintain homeostasis (Oomura et al., 1969; Steffens et al., 1972, 1988; Sawchenko, 1998; Beverly et al., 2001; Lindberg et al., 2013; Valassi et al., 2014). This review will focus on the mechanisms underlying hypothalamic glucose sensing and the role of this system in glucose homeostasis.

Glucose is the primary fuel of the brain, thus it is essential to maintain adequate levels for brain function at all times. Hypothalamic glucose sensing neurons were discovered in the 1960s, and there is evidence that they play a role in maintaining cerebral glucose levels (Anand et al., 1964; Oomura et al., 1964; Levin et al., 2004; Fioramonti et al., 2010b). The hypothalamus also receives and integrates input from other central and peripheral glucose sensors (Routh et al., 2013). Interestingly, glucose sensing neurons make up subpopulations of hypothalamic nuclei involved in varied aspects of neuroendocrine function (Fioramonti et al., 2007; Gonzalez et al., 2008; Melnick et al., 2011; Roland and Moenter, 2011; Stanley et al., 2013). This suggests that glucose sensing neurons may contribute to the coordination of nutrient partitioning amongst neuroendocrine systems. 
However, given the need of the brain for glucose, we hypothesize that the main function of hypothalamic glucose sensing neurons is to ensure that brain needs are prioritized above those of other neuroendocrine or bodily functions.

\section{GLUCOSE ENTRY INTO THE BRAIN}

When considering the physiological significance of brain glucose sensing, it is important to consider the regulation of glucose entry into the brain. The saturable glucose transporter isoform1 is the primary glucose transporter at the blood brain barrier (Cardoso et al., 2010). However, the regulation of blood glucose entry is clearly more complicated than simple transport, and suggests the evidence of distinct diffusion barriers as will be discussed below (Mullier et al., 2009; Langlet et al., 2013). As a result, glucose concentrations in the brain are lower than that of the periphery. A landmark study by Silver and Erecinska in the 1990s showed that ventromedial hypothalamic (VMH) glucose levels in anesthetized rats were $\sim 2.5 \mathrm{mM}$ at baseline $(\sim 7.6 \mathrm{mM}$ blood glucose due to the hyperglycemic effects of anesthesia) and $0.16 \mathrm{mM}$ during hypoglycemia ( $\sim 2.8 \mathrm{mM}$ blood glucose). In this study, $\mathrm{VMH}$ glucose levels never exceeded $4.5 \mathrm{mM}$ even when blood glucose was raised to $20 \mathrm{mM}$ (Silver and Erecinska, 1994). Later microdialysis studies using the zero net flux technique in awake animals indicated that brain glucose levels at peripheral euglycemia $(\sim 5.5 \mathrm{mM})$ were $\sim 1.5-2 \mathrm{mM}$, not only in the hypothalamus but the hippocampus and striatum as well (McNay and Gold, 1999; McNay et al., 2000, 2001; De Vries et al., 2003). Brain glucose varies with blood glucose, declining to $\sim 0.7 \mathrm{mM}$ after an overnight fast. During peripheral hypoglycemia, hypothalamic glucose fell to $\sim 0.3 \mathrm{mM}$ (Dunn-Meynell et al., 2009). These studies indicate that hypothalamic glucose levels range from $\sim 0.2$ to $4.5 \mathrm{mM}$ as blood glucose levels vary from pathological hypoglycemia to hyperglycemia. Physiological hypothalamic glucose levels vary from $\sim 0.7$ to $2.5 \mathrm{mM}$ between the fasted and fed state. This issue is important because although glucose concentration in the hypothalamus was first measured nearly 20 years ago, until fairly recently the majority of in vitro studies of glucose sensing neurons still used standard extracellular solutions containing 10-20 mM glucose. These glucose concentrations would even be considered analogous to diabetes when occurring in the blood. Thus, experimental conditions need to be considered when evaluating the relevance of the results obtained from studies of glucose sensing neurons.

There are several likely reasons for the resistance to studies of neurons in vitro using physiologically relevant glucose concentrations. One technical reason is that lower glucose concentrations were thought to be damaging to neurons in vitro or to cause neuronal silencing (Mobbs et al., 2001). This was reflected by the fact that until recently it was impossible to purchase stock neuronal culture media containing less than $20 \mathrm{mM}$ glucose (media is now available without glucose to allow investigator control). However, for over 15 years our laboratory and others have routinely studied hypothalamic neurons in brain slices or after dissociation using $\sim 2 \mathrm{mM}$ glucose in the bathing medium with no evidence of neuronal damage or silencing (Levin et al., 1993; Routh et al., 1997; Song et al., 2001; Kang et al., 2004; Wang et al., 2004; Song and Routh, 2005, 2006; Burdakov et al., 2006; Canabal et al., 2007b; Fioramonti et al., 2007; Gonzalez et al., 2008; Cotero and Routh, 2009; Cotero et al., 2009; Murphy et al., 2009a,b; Melnick et al., 2011; Medeiros et al., 2012; Karnani et al., 2013; Vazirani et al., 2013). In fact, we find that glucose concentrations of $5 \mathrm{mM}$ and higher obscure glucose sensing in some subtypes of glucose sensing neurons (Canabal et al., 2007a).

A more compelling argument for the use of higher glucose concentrations relates to brain regions near circumventricular organs. One important example is the arcuate nucleus (ARC) within the $\mathrm{VMH}$ which surrounds the median eminence. $\mathrm{VMH}$ glucose levels discussed above are often taken to reflect those within the larger ventromedial nucleus (VMN), which lies dorsal to the ARC. In contrast, since the median eminence possesses a fenestrated endothelium it was assumed that ARC glucose levels would be more similar to that of the blood than to the VMN. However, Dunn-Meynell et al., showed that ARC and VMN glucose levels do not differ (Dunn-Meynell et al., 2009). In this regard, the work of Vincent Prevot and colleagues also deserves careful consideration (Mullier et al., 2009). This group has convincingly demonstrated that differential organization and expression of the tight junction proteins within the ependymal cells which line the third ventricle and the median eminence leads to distinct patterns of diffusion from blood and cerebrospinal fluid. When blue Evans dye was injected into the blood, staining was restricted to the median eminence and did not diffuse into the ARC. In contrast, when the dye was injected into the third ventricle, staining was present in the ARC but not in the adjacent VMN. These data suggest that distinct diffusion barriers exist between the cerebrospinal fluid, circumventricular organs (e.g., median eminence) and the brain (even between adjacent brain regions). However, the physiological significance of diffusion from cerebrospinal fluid to the ARC is unclear given that the cerebrospinal fluid is thought predominantly to drain the brain. An even more intriguing observation from these investigators is that these barriers are not constant under all physiological conditions. For example, during fasting and glucoprivation the structural components of these hypothalamic diffusion barriers were altered such that ARC glucose levels significantly exceeded those in the VMN, although they did not reach blood levels. Furthermore, blood glucose levels appear to play a key role in driving these structural changes in the blood- and cerebrospinal fluid-brain barriers (Langlet et al., 2013). Together, these data indicate that while brain glucose levels are clearly lower than those of the blood, there exist privileged routes for glucose diffusion to distinct brain regions (e.g., from cerebrospinal fluid to ARC but not VMN) which are regulated by nutritional status. These observations also underscore the putative role of central glucose sensing in modulating glucose levels in order to meet the needs of the brain.

\section{CELLULAR MECHANISMS OF GLUCOSE SENSING}

The existence of glucose sensing neurons was suggested by 2 independent groups in 1964, one using cats and the other dogs (Anand et al., 1964; Oomura et al., 1964). In these studies, reciprocal changes in single unit activity were measured in the $\mathrm{VMH}$ and lateral hypothalamus (regions formerly called the "satiety" and "feeding" centers, respectively) during intravenous glucose 
or insulin injections. Glucose increased neuronal activity in the $\mathrm{VMH}$ while the converse occurred in the lateral hypothalamus. Later work from Oomura's laboratory demonstrated that hypothalamic neurons were directly regulated by glucose in vitro. This group coined the terms glucose responsive for neurons that increased their activity with increased glucose and glucose sensitive for those that decreased their activity as glucose increased (Oomura et al., 1964). Today, these subtypes of glucose sensing neurons are more commonly referred to respectively as glucoseexcited (GE) or glucose-inhibited (GI) neurons based on their response to physiological changes in extracellular glucose (Song et al., 2001; Kang et al., 2004; Wang et al., 2004; Burdakov et al., 2005; Melnick et al., 2011). The following discussion of glucose sensing mechanism will focus primarily on studies using physiological glucose concentrations unless this information is not available. These data are summarized in Table 1. We are defining physiological glucose concentration as being below $5 \mathrm{mM}$ in order to account for variability in blood or cerebrospinal fluid to brain glucose ratio under differing physiological conditions. Data from studies which used tissue or cellular preparations which do not discriminate between the ARC and VMN will be referred to as "VMH," whereas studies in which neuronal location was verified

Table 1 | Putative role of glucose-inhibited and glucose-excited neurons in substrate partitioning during energy deficit.

\begin{tabular}{|c|c|c|c|c|c|}
\hline $\begin{array}{l}\text { Nuclei/Peptide } \\
\text { phenotype }\end{array}$ & $\begin{array}{l}\text { Glucose } \\
\text { Sensing } \\
\text { phenotype }\end{array}$ & $\begin{array}{l}\text { Mechanism of } \\
\text { glucose sensing }\end{array}$ & $\begin{array}{l}\text { Putative effect on } \\
\text { brain fuel supply } \\
\text { during energy deficit }\end{array}$ & $\begin{array}{l}\text { Mechanism by } \\
\text { which brain fuel } \\
\text { may be altered }\end{array}$ & Representative references \\
\hline VMN nNOS & Inhibited & NO/AMPK/Cl- channel & Increase & $\begin{array}{l}\text { Glucagon, } \\
\text { epinephrine secretion }\end{array}$ & $\begin{array}{l}\text { Song et al., 2001; Song and Routh, } \\
\text { 2006; Murphy et al., 2009a; } \\
\text { Fioramonti et al., 2010a, } 2013\end{array}$ \\
\hline LH orexin & Inhibited & $\begin{array}{l}\text { Metabolism } \\
\text { independent } \\
\mathrm{K}^{+} \text {channel }\end{array}$ & Increase & $\begin{array}{l}\text { Reward feeding } \\
\text { Arousal }\end{array}$ & $\begin{array}{l}\text { Antunes et al., 2001; Burdakov } \\
\text { et al., 2005; Harris et al., 2005; } \\
\text { Gonzalez et al., 2008; Williams } \\
\text { et al., 2008; Sheng et al., } 2014\end{array}$ \\
\hline LH NPY & Inhibited & $\mathrm{K}^{+}$channel & $?$ & & Marston et al., 2011 \\
\hline LH GABA & Inhibited & $\begin{array}{l}\text { Metabolism } \\
\text { independent } \\
\text { Mixed ionic } \\
\text { conductance }\end{array}$ & $?$ & $?$ & Karnani et al., 2013 \\
\hline $\begin{array}{l}\text { PVN pre- } \\
\text { autonomic }\end{array}$ & Inhibited & Unknown & $?$ & $?$ & Melnick et al., 2011 \\
\hline $\mathrm{LH} M C H$ & Excited & $\mathrm{K}^{+}$channel & Decrease & $\begin{array}{l}\text { Anabolic (increase fat } \\
\text { mass)* }\end{array}$ & $\begin{array}{l}\text { Burdakov et al., 2005; Naufahu } \\
\text { et al., } 2013\end{array}$ \\
\hline $\begin{array}{l}\text { PVN pre- } \\
\text { autonomic }\end{array}$ & Excited & $\begin{array}{l}\text { KATP independent } \\
\text { Non-selective cation } \\
\text { channel }\end{array}$ & $?$ & $?$ & Melnick et al., 2011 \\
\hline
\end{tabular}

The overall hypothesis presented here is that during energy deficit the glucose-sensing function of these neurons reinforces the mechanisms which provide brainspecific fuels while reducing the drive for other fuel consuming neuroendocrine systems. The predictions regarding the putative effect on brain fuel supply and underlying mechanisms are based on net positive input to downstream circuitry and would be reversed if their net effect was inhibitory.

*While MCH neurons increase food intake, they are associated with anabolic processes which could divert fuel away from the brain. 
visually or via microdissection as being from one region or the other will be referred to as such.

\section{GLUCOSE-EXCITED (GE) NEURONS}

GE neurons are found in many hypothalamic regions including the ARC, VMN, anterior hypothalamus, paraventricular nucleus, and the lateral hypothalamus (Oomura et al., 1964; Ashford et al., 1990a,b; Shian and Lin, 1991; Burdakov et al., 2005; Melnick et al., 2011; Roland and Moenter, 2011). The neurotransmitter phenotype of VMN GE neurons is largely unknown and there are conflicting reports regarding whether ARC POMC neurons are GE neurons (Wang et al., 2004; Claret et al., 2007; Fioramonti et al., 2007; Parton et al., 2007). In contrast, GE neurons have been found among the gonadotropin releasing hormone neurons $(\mathrm{GnRH})$ of the anterior hypothalamus (Roland and Moenter, 2011; Beall et al., 2012), the preautonomic neurons in the paraventricular nucleus (Melnick et al., 2011), and the melanin concentrating hormone neurons of the lateral hypothalamus (Burdakov et al., 2005). The mechanism underlying glucose sensing by VMH GE neurons has been the most extensively characterized. Michael Ashford was the first to show that the majority of these GE neurons utilize a glucose sensing mechanism similar to that of the pancreatic $\beta$ - cell (Ashford et al., 1990a). That is, like the $\beta$-cell, increased glucose metabolism raises the ATP/ADP ratio and closes the ATP sensitive potassium channel (KATP) leading to depolarization. Despite the fact that Ashford's original studies were performed using non-physiological glucose concentrations, his findings have stood the test of time (and glucose concentration) (Song et al., 2001). Barry Levin's laboratory demonstrated a second important similarity between many VMH GE neurons and the pancreatic $\beta$-cell: the initial phosphorylation of glucose to glucose-6-phosphate is catalyzed by the pancreatic form of hexokinase IV, glucokinase (Dunn-Meynell et al., 2002; Kang et al., 2006). In addition to a lower affinity for glucose than other hexokinases, glucokinase is not subject to end-product inhibition. This allows for activity at a rate proportional to glucose concentration (Magnuson, 1990). Thus, the presence of glucokinase is often used to predict glucose sensing in neuronal populations (Navarro et al., 1996; Yang et al., 1999; Lynch et al., 2000; Maekawa et al., 2000; Mobbs et al., 2001; Dunn-Meynell et al., 2002; Levin, 2002; Penicaud et al., 2002; Ramonet et al., 2004; Balfour et al., 2006; Kang et al., 2006; Zhou et al., 2010; Beall et al., 2012).

In addition to the ubiquitous glucose transporter 3 (GLUT3), subpopulations of VMH GE neurons also express GLUT2 and the insulin-sensitive GLUT4. Interestingly, a fairly large percentage of GE neurons express both GLUT4 and the insulin receptor (Kang et al., 2004). About 25\% of VMH GE neurons possess the sodium glucose co-transporter (SGLT) which could couple glucose uptake with membrane depolarization (Kang et al., 2004). The cellular fuel sensor AMP activated protein kinase (AMPK) may mediate glucose sensing in some GE neurons. For example AMPK dependent glucose sensing has been reported for POMC neurons, as well as for the GnRH neurons in the anterior hypothalamus (Claret et al., 2007; Roland and Moenter, 2011; Beall et al., 2012). Finally, the KATP channel does not mediate glucose sensing in all GE neurons. GnRH neurons and PVN GE neurons use a non-selective cation channel, while the melanin-concentrating hormone neurons use an unidentified K channel (Burdakov et al., 2005; Melnick et al., 2011; Roland and Moenter, 2011). Thus, while many GE neurons could be considered the brain's "pancreatic $\beta$-cell," there is clearly a high degree of heterogeneity within this category of glucose sensing neurons.

\section{GLUCOSE-INHIBITED (GI) NEURONS}

GI neurons are also widely dispersed throughout the hypothalamus, including the VMN, ARC, paraventricular nucleus, dorsomedial nucleus, and the lateral hypothalamus (Song et al., 2001; Burdakov et al., 2005; Song and Routh, 2006; Fioramonti et al., 2007; Williams et al., 2008; Marston et al., 2011; Melnick et al., 2011). There are two broad categories of GI neurons, those whose activity is regulated by glucose metabolism (e.g., by changes in ATP) and those that respond to the glucose molecule itself. The metabolism dependent GI neurons most likely utilize GK since, like GE neurons, the majority of GI neurons express GK (DunnMeynell et al., 2002; Kang et al., 2006). Moreover, like GE neurons, subpopulations of metabolism dependent GI neurons also express GLUT2, GLUT4, SGLT2, and/or the insulin receptor (Kang et al., 2004). The most studied of the metabolism dependent GI neurons are located in the VMH. These GI neurons are activated in low glucose via an interaction between AMPK and the gaseous messenger nitric oxide (NO) which leads to chloride channel closure, membrane depolarization, and increased action potential frequency (Song et al., 2001; Song and Routh, 2005; Murphy et al., 2009a; Fioramonti et al., 2010a). VMH NO production by the neuronal NO synthase (nNOS) and NO signaling through its receptor, soluble guanylyl cyclase (sGC) are critical for both glucose sensing by GI neurons and the in vivo counterregulatory response (CRR) to hypoglycemia suggesting a role for these GI neurons in hypoglycemia detection (Murphy et al., 2009a; Fioramonti et al., 2010a, 2013). There is also a very significant overlap between VMH NO producing neurons and GI neurons (Canabal et al., 2007b). Thus, while the peptide neurotransmitter phenotype of these GI neurons remains unclear, it is reasonable to refer to them as nNOS-GI neurons based on their gaseous transmitter phenotype.

The above studies provided consistent results using either electrophysiological recordings of VMN GI neurons in brain slices or membrane potential dye imaging in freshly isolated $\mathrm{VMH}$ neurons. The electrophysiological experiments were performed on visually identified VMN neurons; whereas studies using isolated VMH neurons did not allow discrimination between VMN and ARC neurons. It is likely that mechanistic data concerning AMPK-NO signaling obtained from imaging isolated $\mathrm{VMH}$ neurons reflect VMN vs. ARC GI neurons for several reasons. Technically, VMN neurons vastly outnumber ARC neurons in this preparation and thus the significant majority of GI neurons analyzed would be VMN- vs. ARC-GI neurons. Moreover, the ARC neuropeptide Y (NPY)/agouti-related peptide (AgRP) co-expressing neurons, half of which are GI neurons, do not express nNOS nor do changes in intracellular AMPK appear to affect their activity (Sternson et al., 2005; Fioramonti et al., 2007; Leshan et al., 2012). Thus, together these data suggest distinct glucose sensing mechanisms for VMN nNOS-GI and ARC 
NPY/AgRP-GI neurons. The exact cellular mechanism underlying glucose sensing in the ARC NPY/AgRP-GI neurons is not known. However, it could still be argued that regardless of what the mechanism is ultimately determined to be, the NPY/AgRP-GI neurons are metabolism-dependent since they are clearly regulated by changes in AMPK activity in presynaptic terminals synapsing onto NPY/AgRP neurons (Yang et al., 2011).

Denis Burdakov's laboratory has extensively characterized the metabolism-independent, orexin expressing GI neurons, which are only found in the lateral, perifornical and dorsomedial hypothalamus (Burdakov et al., 2005; Gonzalez et al., 2008; Williams et al., 2008). Orexin neurons are equally inhibited by glucose and by the non-metabolizable glucose analog, 2-deoxyglucose. Thus, they respond to the glucose molecule itself rather than downstream metabolites (Gonzalez et al., 2008; Sheng et al., 2014). Glucose clearly activates a leak tandem-pore potassium (K2P) channel in these neurons (Burdakov et al., 2006; González et al., 2009). Moreover, Twik-related acid-sensitive potassiumlike (TASK) 1/3 channels, which belong to the K2P ion channel family, regulate high frequency firing in orexin neurons. However, TASK $1 / 3$ channels do not appear to be critical for glucose sensing (González et al., 2009). Thus, at the present time the precise ion channel which mediates glucose inhibition in metabolism-independent GI neurons remains to be determined. Interestingly, there are two different glucose responses for metabolism-independent GI neurons. A non-adapting response is characterized by sustained glucose inhibition, while "adapting" GI neurons are transiently inhibited when glucose concentration rises but resume firing action potentials after several minutes in high glucose (Williams et al., 2008). The adaptive response appears to be due to a spontaneous decrease in inhibitory $\mathrm{K}^{+}$currents (Williams et al., 2008). In addition to the orexin neurons, GI neurons also exist within the NPY and gamma-aminobutyric acid (GABA) neurons of the lateral hypothalamus (Marston et al., 2011; Karnani et al., 2013). The GABA-GI neurons are also metabolism independent. However, they are distinct from the orexin-GI neurons in that the glucose sensitive conductance appears to be carried by a mixture of ion channels (Marston et al., 2011). It is not known whether the lateral hypothalamic NPYGI neurons are metabolism dependent or independent (Karnani et al., 2013). The paraventricular nucleus GI neurons may also be metabolism independent because they do not appear to express GK (Stanley et al., 2013).

\section{GLUCOSE SENSING GLIAL CELLS}

Neurons are not the only glucose sensitive cells within the brain. An increasing body of knowledge suggests that glucose sensing by hypothalamic glial cells may play an important role in glucose and energy homeostasis. For example, the data discussed above indicates that the cells composing the blood brain barrier are responsive to changes in glucose (Langlet et al., 2013). Specialized ependymal cells known as tanycytes which line the third ventricle express GK, GLUT2 and KATP channels, suggesting that they are capable of sensing glucose (Garcia et al., 2003). In support of this, glucose increases intracellular calcium levels within cultured tanycytes (Orellana et al., 2012). Hypothalamic GK inhibition by alloxan in vivo reduces food intake, impairs the hyperglycemic response to a glucoprivic challenge and destroys tanycytes; all of which reverse 2 weeks after alloxan injection. These data suggest that hypothalamic tanycytes play a role in the physiological response to hypoglycemia (Sanders et al., 2004). Astrocytes also play a role in glucose sensing. Numerous studies suggest that the glucose transporter 2 (GLUT2) plays a role in hypothalamic glucose sensing (Garcia et al., 2003; Guillod-Maximin et al., 2004; Marty et al., 2005; Bady et al., 2006; Stolarczyk et al., 2010). Interestingly, hypothalamic GLUT2 is primarily expressed in astrocytes (Guillod-Maximin et al., 2004). Thus, it is clear that hypothalamic glucose sensing is a complex system involving coordination between a wide variety of neuronal and glial populations.

\section{REGULATION OF GLUCOSE SENSING BY SIGNALS OF PERIPHERAL ENERGY HOMEOSTASIS HORMONAL SIGNALS OF ENERGY HOMEOSTASIS}

Hypothalamic glucose sensing is modulated by the hormonal milieu which reflects peripheral energy homeostasis. Insulin and the adipose derived hormone leptin, both of which are considered "satiety" hormones, inhibit VMH GE neurons in the presence of high extracellular glucose by opening the KATP channel (Spanswick et al., 1997, 2000). The effect of insulin persisted in physiological glucose concentrations (Cotero and Routh, 2009); however leptin had no effect on VMH GE neurons in $2.5 \mathrm{mM}$ glucose (Wang et al., 2004). Insulin also prevents inhibition of VMH GE neurons when glucose is lowered (Cotero and Routh, 2009; Cotero et al., 2009). Interestingly, hypothalamic insulin infusion suppresses hepatic glucose production in vivo (Rojas and Schwartz, 2014). A role for VMH GE neurons in altered glucose homeostasis is also suggested by the observation that VMH GE neurons from $d b / d b$ mice and $f a / f a$ Zucker rats with peripheral insulin resistance are also insulin resistant (Spanswick et al., 2000; Cotero et al., 2009). Interestingly, ghrelin, which is released from the stomach during hunger, indirectly inhibits ARC POMC (GE?) neurons (Cowley et al., 2003; Ibrahim et al., 2003). Similar effects of ghrelin and leptin on GE neurons is counterintuitive. However, it is well established that leptin activates POMC neurons (Cowley et al., 2001). Moreover, the effect of ghrelin on glucose sensitivity of POMC neurons has not yet been evaluated nor is there agreement as to whether POMC neurons are truly GE neurons (Wang et al., 2004; Fioramonti et al., 2007).

Metabolically relevant hormones also regulate both the activity and the glucose sensitivity of GI neurons. Leptin inhibits ARC NPY/AgRP neurons (50\% of which are GI neurons) as well as lateral hypothalamic orexin-GI neurons (Shiraishi et al., 2000; Yamanaka et al., 2003; Kohno et al., 2007; Louis et al., 2010; Baver et al., 2014). Leptin also blunts the activation of both VMHand lateral hypothalamic orexin-GI neurons by decreased glucose (Murphy et al., 2009b; Sheng et al., 2014). In contrast, activation of VMN GI neurons by decreased glucose is blunted in the neuronal insulin-receptor knockout (NIRKO) mouse (DiggsAndrews et al., 2010) and insulin stimulates NO production by VMH GI neurons in decreased glucose (Canabal et al., 2007b). These observations are consistent with insulin-induced 
potentiation of the response to low glucose in these neurons. The effect of insulin on lateral hypothalamus orexin-GI neurons is not clear. These neurons are clearly activated by insulin-induced hypoglycemia; however whether this is simply because they are GI neurons or whether insulin is having an independent effect is not known (Griffond et al., 1999; Moriguchi et al., 1999; Cai et al., 2001; Zhao et al., 2005). As predicted given the inhibitory effect of leptin, ghrelin activates both NPY-GI and orexin-GI neurons (Kohno et al., 2003; Yamanaka et al., 2003). Ghrelin also increases the activation of orexin-GI neurons in low glucose (Sheng et al., 2014).

\section{NUTRIENTS OTHER THAN GLUCOSE}

Hypothalamic glucose sensing neurons also respond to other nutrient-related signals in addition to glucose. Within the $\mathrm{VMH}$, there is overlap between GE and GI neurons and neurons whose activity is altered by free fatty acids and ketones (Wang et al., 2005; Le Foll et al., 2013, 2014). Neuronal fatty acid sensing is consistent with data showing that central fatty acid infusion modulates glucose-induced insulin secretion and peripheral insulin sensitivity (Cruciani-Guglielmacci et al., 2004; Migrenne et al., 2006; Marsollier et al., 2009; Le Foll et al., 2013). In contrast to glucose and fatty acids, direct evidence of amino acid sensing neurons has been elusive. Administration of the branched chain amino acid L-leucine, but not valine, into the third ventricle decreases food intake; an effect which appears to be mediated by the hypothalamic mammalian target of rapamycin (mTOR) (Cota et al., 2006). The mTOR inhibitor rapamycin restores NO production by VMH GI neurons during hyperglycemia suggesting potential overlap in glucose and amino acid sensing pathways in these neurons (Canabal et al., 2007a). Moreover, Blouet et al. demonstrated that direct application of leucine increased the action potential frequency of POMC neurons (Blouet et al., 2009). Taken together these data support the hypothesis that hypothalamic glucose sensing neurons integrate multiple nutrient signals; however this has yet to be definitely shown for amino acids.

\section{PHYSIOLOGICAL ROLE OF GLUCOSE SENSING NEURONS}

While the existence of glucose sensing neurons has been known for half a century (Anand et al., 1964; Oomura et al., 1964), their exact physiological functions remain elusive. In the following discussion, we have attempted to relate what is known about the different subpopulations of glucose sensing neurons with the function of the region or peptide phenotype in which they are found. Table 1 summarizes these data. Our overall hypothesis is that glucose sensitivity within multiple populations of neurons involved in metabolic control enables the brain to broadly reinforce the neurocircuitry which compensates for energy deficit when glucose levels fall. This would be beneficial in order to ensure an adequate neuronal fuel supply (glucose, ketones) at all times.

\section{HYPOGLYCEMIA DETECTION}

When considering a physiological role for glucose sensing neurons, hypoglycemia detection seems an obvious choice, especially since the majority of glucose sensing neurons are most sensitive to a decline in extracellular glucose levels below that which would be seen during normal fed conditions (Song et al., 2001; Wang et al., 2004; Song and Routh, 2005; Murphy et al., 2009b). This hypothesis is also attractive when considering that glucose is the primary fuel of the brain and that hypoglycemia clearly has deleterious central effects (Languren et al., 2013). Insulininduced hypoglycemia increases cfos activation in a number of hypothalamic nuclei, including the ARC, the paraventricular and dorsomedial nuclei and the lateral hypothalamus (Niimi et al., 1995; Diggs-Andrews et al., 2010; Fergani et al., 2014). Moreover, hypoglycemia or central glucoprivation induces $c$ fos expression in several known hypothalamic glucose sensing populations including the lateral hypothalamic orexin neurons as well as NPY neurons in the ARC, dorsomedial nucleus and lateral hypothalamus (Cai et al., 2001; Ferenczi et al., 2010; Marston et al., 2011). Interestingly, although the VMN contains GI neurons and plays a role in hypoglycemia detection, $c f o s$ activation was not detected in this brain region following insulin-induced hypoglycemia or glucoprivation (Niimi et al., 1995; Borg et al., 1997; Diggs-Andrews et al., 2010; Zhu et al., 2010; Szepietowska et al., 2011; Stanley et al., 2013). One reason for this apparent discrepancy may be because activation of VMN nNOS-GI neurons by decreased glucose requires the NO-sGC pathway, which may not be represented by $c f o s$ activation.

Although VMN cfos does not increase after hypoglycemia, functional studies support a key role for VMN GI neurons in the CRR. For example, repetitive hypoglycemic episodes shift the glycemic threshold for initiation of the CRR to lower glucose levels (Dagogo-Jack et al., 1993; Cryer, 2013; Moheet et al., 2014). Similarly, after recurrent hypoglycemia VMN GE and GI neurons show blunted inhibition or activation, respectively, as glucose levels decline (Song and Routh, 2006; Kang et al., 2008; Fioramonti et al., 2010b). Moreover, VMH lactate infusion in vivo blunts the CRR while lactate perfusion in vitro blunts activation of VMN GI neurons by decreased glucose (Song and Routh, 2005). VMH NO signaling is critical for glucose sensing by VMN nNOS-GI neurons as well as for the full CRR. That is, nNOS inhibition prevents activation of VMN nNOS-GI neurons by decreased glucose and neurons which are activated by decreased glucose are not detectable in brain sections from nNOS knockout mice (Fioramonti et al., 2010a). Similarly, the CRR is significantly impaired in nNOS knockout mice, after VMH NOS or sGC inhibition, or when NO-sGC signaling is disrupted by a post-translational modification of sGC known as $\mathrm{S}$-nitrosation which renders it NO resistant (Fioramonti et al., 2010a, 2013). Interestingly, when S-nitrosation during recurrent hypoglycemia is prevented both glucose sensing by $\mathrm{VMH}$ GI neurons as well as the CRR are preserved. Taken together, these data suggest a clear role for GI, and in particular VMN nNOS-GI, neurons in detecting hypoglycemia and initiating the CRR.

\section{FASTING AND STARVATION}

In addition to hypoglycemia detection, another potential role for glucose sensing neurons is to maintain the brain's energy supply during starvation. In fact, since insulin-induced hypoglycemia is an iatrogenic consequence of treating Type 1 and advanced Type 2 Diabetes Mellitus in the modern world, glucose sensing 
neurons probably evolved as a defense against starvation. During starvation, the hypothalamic-pituitary-adrenal axis and the sympathetic nervous system play a key role in energy mobilization (Straub et al., 2010). The energetic needs of the body and the brain are first supplied by mobilization of liver glycogen stores for gluconeogenesis. After several hours adipocyte lipolysis provides fatty acids, which then fuel most organ systems. However, the brain cannot utilize fatty acids as fuel. Thus, preserving adequate blood glucose for the brain during starvation is one of the most important actions of the neuroendocrine system. When liver glycogen is depleted, muscle catabolism is initially necessary to provide amino acids as substrates for gluconeogenesis. Muscle catabolism is clearly detrimental in the long term and after several days of starvation, increased conversion of fatty acids to ketones in the liver provides fuel to the brain and spares lean body mass (Straub et al., 2010). It seems likely that glucose sensing neurons, particularly GI neurons, are important for informing the brain of the potential magnitude of a threat to the brain energy supply during starvation and aiding in energy mobilization.

In support of this, in general the hormonal changes which occur during fasting (e.g., reduced leptin and increased ghrelin) activate GI neurons and/or enhance their activation by decreased glucose (Cai et al., 1999; López et al., 2000; Diano et al., 2003; Kohno et al., 2003, 2008; Yamanaka et al., 2003; Murphy et al., 2009b; Sheng et al., 2014). A role for ARC NPY/AgRP-GI neurons in defending the brains energy supply during starvation stands out in particular. Fasting increases NPY gene expression as well as cfos expression and action potential frequency in ARC NPY/AgRP-GI neurons (Mizuno et al., 1999; Takahashi and Cone, 2005; Becskei et al., 2009; Murphy et al., 2009b). Fasting also increases hypothalamic NPY release and the activation of NPY/AgRP-GI neurons in response to decreased glucose (Murphy et al., 2009b). These data are consistent with the overall role of hypothalamic NPY/AgRP neurons to stimulate food intake (Billington and Levine, 1992; White, 1993). NPY expressing neurons are found in several brain regions which regulate energy homeostasis including the ARC and brainstem. However, AgRP expression is restricted to the ARC where it is found in 95\% of the NPY neurons (Broberger et al., 1998). AgRP is an endogenous inhibitor of the melanocortin receptor. Thus, NPY/AgRP neurons oppose the effects of the anorexigenic POMC neurons at their targets. These targets include the hypothalamic paraventricular nucleus; a key site for regulating metabolism and food intake. The corticotrophin releasing hormone neurons which drive the hypothalamic-pituitary-adrenal axis as well as pre-autonomic neurons which activate the sympathetic nervous system reside in the paraventricular nucleus (Steffens et al., 1972, 1988; van Dijk et al., 1994; Ahima et al., 2000; Elmquist, 2001; Watts and Sanchez-Watts, 2002). In addition to opposing POMC neurons, NPY/AgRP neurons regulate energy partitioning and substrate utilization in a melanocortin-independent fashion (Joly-Amado et al., 2012). Importantly, AgRP deficiency impairs ketone body release from the liver during starvation (Warne et al., 2013). AgRP also mediates the gluconeogenic effects of ghrelin (Wang et al., 2014). Thus, increased AgRP release, especially in response to low glucose during starvation, may play a role in enhancing gluconeogenesis as well as triggering increased ketone production to fuel the brain. Similarly, increased activation of VMN nNOS-GI neurons during low glucose is consistent with enhanced gluconeogenesis (Fioramonti et al., 2010a). Orexin is associated with enhanced reward-based feeding behavior as well as increased sympathetic activity. Increased activity in low glucose, especially during fasting, is consistent with this line of reasoning (Antunes et al., 2001; Harris et al., 2005; Kelley et al., 2005; Zheng et al., 2007; Choi et al., 2010; Perello et al., 2010; Sheng et al., 2014). Moreover, we have recently shown that low glucose enhances excitatory glutamate neurotransmission onto ventral tegmental area dopamine neurons in an orexin dependent manner (Sheng et al., 2014). This observation strongly supports a role for orexin-GI neurons in reinforcing feeding behavior when glucose levels decline. Finally, since growth hormone is also released during hypoglycemia, it makes sense that growth hormone releasing hormone neurons are also GI neurons (Stanley et al., 2013). Together these data are consistent with an overall role for hypothalamic GI neurons in providing the brain with fuel during energy deficit. An important caveat to the above discussion is that the neurocircuitry which controls autonomic and neuroendocrine systems is extremely complex and its activation should never be considered in "all or none" terms. Rather, the above is a generalization in order to propose a physiological role for glucose sensing neurons and form a framework for designing experiments which test these hypotheses.

\section{LINK NEUROENDOCRINE SYSTEMS WITH GLUCOSE STATUS}

Another putative function for hypothalamic glucose sensing neurons is to prevent activation of neuroendocrine systems which use rather than provide fuel during energy deficit or conversely to allow energy to be diverted to these systems when it will not threaten the brain. For example, this may explain why subpopulations GnRH neurons are glucose sensing (Roland and Moenter, 2011). In contrast to the GI neurons described above, GnRH neurons are excited by glucose. Thus, when glucose levels are sufficient reproductive function is supported. Conversely, during times when food is scarce and glucose levels are low, the glucose sensing function of these neurons would contribute to inhibition of the reproductive axis. Moreover, while melanocortin concentrating hormone neurons stimulate food intake, they are also associated with anabolic processes (increased fat mass, reproduction) which could divert fuel away from the brain (Naufahu et al., 2013). Thus, reduced activity of melanocortin concentration hormone-GE neurons in low glucose is consistent with our overall hypothesis. However, one must use caution when trying to apply this reasoning to all GE or GI neurons because the relationship between the direction of glucose sensing (i.e., excited or inhibited by glucose) will depend on whether that particular glucose sensing neuron is inhibitory or stimulatory to the system in question. This is further evidenced by the observation that both GE and GI neurons are often found in the same hypothalamic nuclei. As mentioned above, the homeostatic mechanisms regulated by the hypothalamus are diverse and extremely complex. Thus, extreme caution is warranted when attempting to generalize the function of hypothalamic GE and GI neurons. Moreover, it is important to 
realize that there will be numerous exceptions to any rule for these systems.

\section{WHAT ABOUT ENERGY SURPLUS?}

The preceding discussion of hypothalamic glucose sensing neurons has focused on their role in sensing energy deficit. The main reasons for this bias are as follows. Although glucose concentration-response curves have only been published for VMH GE and GI neurons, these data suggest that glucose sensing neurons are primarily responsive to decreases in glucose below brain glucose concentrations associated with peripheral euglycemia (Wang et al., 2004; Song and Routh, 2005; Kang et al., 2006; Murphy et al., 2009b). In addition, their glucose sensitivity is altered under conditions associated with a need to sense energy deficit. That is, fasting reduces the inhibitory effect of glucose on VMH GI neurons leading to increased activation in response to smaller declines in glucose (Murphy et al., 2009b). Moreover, the glucose sensitivity of both VMH GE and GI neurons shifts in parallel with the ability of the brain to sense and respond to insulininduced hypoglycemia (Song and Routh, 2005, 2006; Kang et al., 2008; Diggs-Andrews et al., 2010; Fioramonti et al., 2010a,b, 2013). In contrast, there is less known about glucose sensing neurons during hyperglycemia. We found that acute hyperglycemia prevents VMH GI neurons from producing NO and depolarizing in response to decreased glucose as a result of mTOR inhibition of AMPK (Canabal et al., 2007a). Conversely, while inhibition of VMH GE neurons from diabetic $d b / d b$ mice to a maximal glucose decrease to $0.1 \mathrm{mM}$ was identical to that of non-diabetic controls, the inhibition in response to a mid-range decrease $(0.5 \mathrm{mM})$ was significantly enhanced in the diabetic mice (Cotero et al., 2009). Spanswick and colleagues found no difference in glucose sensitivity of VMH GE neurons in Zucker obese $f a / f a$ rats compared to lean $\mathrm{Fa} / \mathrm{Fa}$ rats; however they only evaluated the response of these neurons to a glucose decrease from 10 to $0 \mathrm{mM}$ (Spanswick et al., 2000). Finally, 2 additional subtypes of ARC glucose sensing neurons have been identified which respond to changes in extracellular glucose above $5 \mathrm{mM}$ : the high-GE (HGE) and high-GI (HGI) neurons (Fioramonti et al., 2004). As mentioned above, brain glucose concentrations above $5 \mathrm{mM}$ have never been observed. However, since the permeability of the blood brain barrier changes with nutrient status it is possible that these glucose sensing neurons may play a role in glucose detection under some situations (Langlet et al., 2013). Such a role is consistent with data from Luc Penicaud's group showing that centrally restricted glucose infusion via the carotid artery increased cfos expression in ARC and paraventricular nucleus neurons and astrocytes which was associated with transient peripheral insulin secretion (Guillod-Maximin et al., 2004). Based on the above findings, it is tempting to speculate that the brain has a mechanism for sensing hyperglycemia and modulating peripheral metabolism in response. Furthermore, disrupted glucose sensing in diabetes suggests that glucose sensing neurons may play a role in the pathology of metabolic syndrome. In fact, an enhanced response to glucose deficit during conditions of energy sufficiency or even surplus (e.g., obesity/diabetes) could potentially lead to similar compensatory mechanisms as in response to fasting or starvation. Such changes could further enhance the obese state. However, due to a lack of data such comments are purely speculative at this time.

\section{INTERACTION WITH NON-HYPOTHALAMIC GLUCOSE SENSORS}

While the focus of this review is on hypothalamic glucose sensing neurons, glucose sensing neurons are also found in many other brain regions including the amygdala (Nakano and Oomura, 1986; Zhou et al., 2010), nucleus solitarius (Adachi et al., 1984) and midbrain (Levin, 2000). Moreover, although glucose sensing neurons per se have not been identified in the hindbrain, neurons within this region clearly respond to glucoprivation (Ritter et al., 1998, 2011; Routh et al., 2013). There are also glucose sensors located in numerous peripheral sites including the carotid bodies (Alvarez-Buylla and de Alvarez-Buylla, 1998; Pardal and Lopez-Barneo, 2002; Lopez-Barneo, 2003), portalmesenteric vein (Donovan et al., 1994; Hevener et al., 1997; Matveyenko and Donovan, 2006) and intestine (Sayegh et al., 2004; Raybould, 2007; Ackroff et al., 2010). The regulation of glucose homeostasis clearly involves integration of information from multiple glucose sensing regions. For example, the hypothalamus, hindbrain and portal-mesenteric vein glucose sensors are all critical for hypoglycemia detection and full initiation of the CRR (Routh et al., 2013). Unraveling the physiological function of the many glucose sensing brain regions and how they work together is an evolving field which requires a great deal more work in order to understand.

\section{CONCLUSION: THE SELFISH BRAIN}

In conclusion, the hypothalamus is the primary site of integration for the neuroendocrine and autonomic responses which maintain energy and glucose homeostasis. Within the hypothalamus sensory neurons respond to circulating nutrients and hormones in order to inform the brain regarding peripheral metabolic homeostasis. The presence of glucose sensing neurons within the hypothalamus suggests a sensitive mechanism for maintaining a constant glucose supply to the brain. There is evidence for a role of glucose sensing neurons in hypoglycemia detection and initiation of the CRR during modern iatrogenic hypoglycemia (Song and Routh, 2006; Fioramonti et al., 2010a,b, 2013; Routh et al., 2013). However, it is likely that glucose sensing neurons actually evolved to protect the brain during intermittent starvation. For example, fasting increases the activation of NPY/AgRP-GI and orexin-GI neurons by decreased glucose (Murphy et al., 2009b). This could provide glucose for the brain in several ways; including increased food intake, initiating gluconeogenesis and mediating the shift to ketogenesis should the threat be sufficient (Beck, 2000; JolyAmado et al., 2012; Warne et al., 2013; Sheng et al., 2014; Wang et al., 2014). Should similar fasting-induced changes in the glucose sensitivity of VMN nNOS- and growth hormone releasing hormone-GI neurons occur, this could also contribute to ensuring adequate fuel to the brain (Cai et al., 1999; Fioramonti et al., 2010a; Stanley et al., 2013). In contrast, other subtypes of glucose sensing neurons may divert energy away from competing systems (e.g., reproductive axis Roland and Moenter, 2011) when glucose levels are low. On the other hand, when the energy needs of the brain are met, the response of glucose sensing neurons to 
low glucose may be "deactivated" as seen for the effect of leptin and insulin on VMH GI and GE neurons, respectively (Cotero and Routh, 2009; Murphy et al., 2009b). Thus, we hypothesize that during energy deficit glucose sensing neurons are enlisted in order to enable the brain to prioritize its own energy needs at the expense of other energy requiring systems. However, clearly much work remains to determine the viability of our hypothesis.

\section{AUTHOR CONTRIBUTIONS}

VHR provided the original intellectual conception for the work and drafted and revised the manuscript. Lihong Hao, Ammy M. Santiago, Zhenyu Sheng and Chunxue Zhou provided intellectual discussion during conception and provided critical revision of the draft. All authors provide final approval and agree to be accountable for all aspects of the work in ensuring that questions related to the accuracy or integrity of any part of the work are appropriately investigated and resolved.

\section{ACKNOWLEDGMENTS}

Supported in part by NIDDK RO1 DK81538, the American Heart Association Grant in Aid 14GRNT20380639, and the NJ Health Foundation.

\section{REFERENCES}

Ackroff, K., Yiin, Y.-M., and Sclafani, A. (2010). Post-oral infusion sites that support glucose-conditioned flavor preferences in rats. Physiol. Behav. 99, 402-411. doi: 10.1016/j.physbeh.2009.12.012

Adachi, A., Shimizu, N., Oomura, Y., and Kobashi, M. (1984).Convergence of heptoportal glucose-sensitive afferent signals to glucose-sensitive units within the nucleus of the solitary tract. Neurosci. Lett. 46, 215-218. doi: 10.1016/03043940(84)90444-0

Ahima, R. S., Saper, C. B., Flier, J. S., and Elmquist, J. K. (2000). Leptin regulation of neuroendocrine systems. Front. Neuroendocrinol. 21:197. doi: 10.1006/frne.2000.0197

Alvarez-Buylla, R., and de Alvarez-Buylla, E. R. (1998). Carotid sinus receptors participate in glucose homeostasis. Respir. Physiol. 72, 347-360. doi: 10.1016/0034-5687(88)90093-X

Anand, B. K., China, G. S., Sharma, K. N., Dua, S., and Singh, B. (1964). Activity of single neurons in the hypothalamus feeding centers: effect of glucose. Am. J. Physiol. 2207, 1146-1154.

Antunes, V. R., Brailoiu, G. C., Kwok, E. H., Scruggs, P., and Dun, N. J. (2001). Orexins/hypocretins excite rat sympathetic preganglionic neurons in vivo and in vitro. Am. J. Physiol. Regul. Integr. Comp. Physiol. 281, R1801-R1807.

Ashford, M. L. J., Boden, P. R., and Treherne, J. M. (1990a). Glucose-induced excitation of hypothalamic neurones is mediated by ATP-sensitive $\mathrm{K}^{+}$channels. Pfugers Arch. 415, 479-483.

Ashford, M. L. J., Boden, P. R., and Treherne, J. M. (1990b). Tolbutamide excites rat glucoreceptive ventromedial hypothalamic neurones by indirect inhibition of ATP-sensitive $\mathrm{K}^{+}$channels. Br. J. Pharmacol. 101, 531-540. doi: 10.1111/j.14765381.1990.tb14116.x

Bady, I., Marty, N., Dallaporta, M., Emery, M., Gyger, J., Tarussio, D., et al. (2006). Evidence from Glut2-Null mice that glucose is a critical physiological regulator of feeding. Diabetes 55, 988-995. doi: 10.2337/diabetes.55.04.06.db05-1386

Balfour, R. H., Hansen, A. M. K., and Trapp, S. (2006). Neuronal responses to transient hypoglycaemia in the dorsal vagal complex of the rat brainstem. J. Physiol. 570, 469-484. doi: 10.1113/jphysiol.2005.098822

Baver, S. B., Hope, K., Guyot, S., Bjørbaek, C., Kaczorowski, C., and O'Connell, K. M. S. (2014). Leptin Modulates the intrinsic excitability of AgRP/NPY neurons in the arcuate nucleus of the hypothalamus. J. Neurosci. 34, 5486-5496. doi: 10.1523/JNEUROSCI.4861-12.2014

Beall, C., Hamilton, D., Gallagher, J., Logie, L., Wright, K., Soutar, M., et al. (2012). Mouse hypothalamic GT1-7 cells demonstrate AMPK-dependent intrinsic glucose-sensing behaviour. Diabetologia 55, 2432-2444. doi: 10.1007/s00125012-2617-y
Beck, B. (2000). Neuropeptides and obesity. [Review] [170 refs]. Nutrition 16, 916-923. doi: 10.1016/S0899-9007(00)00410-X

Becskei, C., Lutz, T. A., and Riediger, T. (2009). Blunted fasting-induced hypothalamic activation and refeeding hyperphagia in late-onset obesity. Neuroendocrinology 90, 371-382. doi: 10.1159/000251723

Beverly, J. L., De Vries, M. G., Bouman, S. D., and Arseneau, L. M. (2001). Noradrenergic and GABAergic systems in the medial hypothalamus are activated during hypoglycemia. Am. J. Physiol. 280, R563-R569.

Billington, C. J., and Levine, A. S. (1992). Hypothalamic neuropeptide Y regulation of feeding and energy metabolism. Curr. Opin. Neurobiol. 2, 847-851. doi: 10.1016/0959-4388(92)90144-A

Blouet, C., Jo, Y.-H., Li, X., and Schwartz, G. J. (2009). Mediobasal Hypothalamic leucine sensing regulates food intake through activation of a hypothalamusbrainstem circuit. J. Neurosci. 29, 8302-8311. doi: 10.1523/JNEUROSCI.166809.2009

Borg, M. A., Sherwin, R. S., Borg, W. P., Tamborlane, W. V., and Shulman, G. I. (1997). Local ventromedial hypothalamus glucose perfusion blocks counterregulation during systemic hypoglycemia in awake rats. J. Clin. Invest. 99, 361-365. doi: 10.1172/JCI119165

Broberger, C., Johansen, J., Johansson, C., Schalling, M., and Hokfelt, T. (1998) The neuropeptide Y/agouti gene-related protein (AGRP) brain circuitry in normal, anorectic, and monosodium glutamate-treated mice. Proc. Natl. Acad. Sci. U.S.A. 95, 15043-15048. doi: 10.1073/pnas.95.25.15043

Burdakov, D., Gerasimenko, O., and Verkhratsky, A. (2005). Physiological Changes in glucose differentially modulate the excitability of hypothalamic melaninconcentrating hormone and orexin neurons in situ. J. Neurosci. 25, 2429-2433. doi: 10.1523/JNEUROSCI.4925-04.2005

Burdakov, D., Jensen, L. T., Alexopoulos, H., Williams, R. H., Fearon, I. M., O’Kelly, I., et al. (2006). Tandem-Pore $\mathrm{K}^{+}$channels mediate inhibition of orexin neurons by glucose. Neuron 50, 711-722. doi: 10.1016/j.neuron.2006.04.032

Cai, X. J., Evans, M. L., Lister, C. A., Leslie, R. A., Arch, J. R., Wilson, S., et al. (2001) Hypoglycemia activates orexin neurons and selectively increases hypothalamic orexin-B levels: responses inhibited by feeding and possibly mediated by the nucleus of the solitary tract. Diabetes 50, 105-112. doi: 10.2337/diabetes.50.1.105

Cai, X. J., Widdowson, P. S., Harrold, J., Wilson, S., Buckingham, R. E., Arch, J. R., et al. (1999). Hypothalamic orexin expression: modulation by blood glucose and feeding. Diabetes 48, 2132-2137. doi: 10.2337/diabetes.48. 11.2132

Canabal, D. D., Potian, J. G., Duran, R. G., McArdle, J. J., and Routh, V. H. (2007a). Hyperglycemia impairs glucose and insulin regulation of nitric oxide production in glucose-inhibited neurons in the ventromedial hypothalamus. Am. J. Physiol. Regul. Integr. Comp. Physiol. 293, R592-R600. doi: 10.1152/ajpregu.00207.2007

Canabal, D. D., Song, Z., Potian, J. G., Beuve, A., McArdle, J. J., and Routh, V. H. (2007b). Glucose, insulin and leptin signaling pathways modulate nitric oxide (NO) synthesis in glucose-inhibited (GI) neurons in the ventromedial hypothalamus (VMH). J. Physiol. Regul. Integr. Comp. Physiol. 292, R1418-R1428. doi: 10.1152/ajpregu.00216.2006

Cardoso, F. L., Brites, D., and Brito, M. A. (2010). Looking at the blood-brain barrier: molecular anatomy and possible investigation approaches. Brain Res. Rev. 64, 328-363. doi: 10.1016/j.brainresrev.2010.05.003

Choi, D. L., Davis, J. F., Fitzgerald, M. E., and Benoit, S. C. (2010). The role of orexin-A in food motivation, reward-based feeding behavior and food-induced neuronal activation in rats. Neuroscience 167, 11-20. doi: 10.1016/j.neuroscience.2010.02.002

Claret, M., Smith, M. A., Batterham, R. L., Selman, C., Choudury, A. I., Fryer, L. G., et al. (2007). AMPK is essential for energy homeostasis regulation and glucose sensing by POMC and AgRP neurons. J. Clin. Invest. 117, 2325-2336. doi: 10.1172/JCI31516

Cota, D., Proulx, K., Smith, K. A. B., Kozma, S. C., Thomas, G., Woods, S. C., et al. (2006). Hypothalamic mTOR signaling regulates food intake. Science 312, 927-930. doi: 10.1126/science.1124147

Cotero, V. E., and Routh, V. H. (2009). Insulin blunts the response of glucoseexcited (GE) neurons in the ventrolateral-ventromedial hypothalamic nucleus (VL-VMN) to decreased glucose. Am. J. Physiol. Endocrinol. Metab. 296, E1101-E1109. doi: 10.1152/ajpendo.90932.2008

Cotero, V. E., Zhang, B. B., and Routh, V. H. (2009). The response of glucose-excited neurones in the ventromedial hypothalamus to decreased glucose is enhanced 
in a murine model of type 2 diabetes mellitus. J. Neuroendocrinol. 22, 65-74. doi: 10.1111/j.1365-2826.2009.01938.x

Cowley, M. A., Smart, J. L., Rubinstein, M., Cerdan, M. G., Diano, S., Horvath, T. L., et al. (2001). Leptin activates anorexigenic POMC neurons through a neural network in the arcuate nucleus. Nature 411, 480-484. doi: 10.1038/35078085

Cowley, M. A., Smith, R. G., Diano, S., Tschop, M., Pronchuk, N., Grove, K. L., et al. (2003). The distribution and mechanism of action of ghrelin in the cns demonstrates a novel hypothalamic circuit regulating energy homeostasis. Neuron 37, 649-661. doi: 10.1016/S0896-6273(03)00063-1

Cruciani-Guglielmacci, C., Hervalet, A., Douared, L., Sanders, N. M., Levin, B. E., Ktorza, A., et al. (2004). Beta oxidation in the brain is required for the effects of non-esterified fatty acids on glucose-induced insulin secretion in rats. Diabetologia 47, 2032-2038. doi: 10.1007/s00125-004-1569-2

Cryer, P. E. (2013). Mechanisms of hypoglycemia-associated autonomic failure in diabetes. N. Eng. J. Med. 369, 362-372. doi: 10.1056/NEJMra1215228

Dagogo-Jack, S. E., Craft, S., and Cryer, P. E. (1993). Hypoglycemiaassociated autonomic failure in insulin-dependent diabetes mellitus. Recent antecedent hypoglycemia reduces autonomic responses to, symptoms of, and defense against subsequent hypoglycemia. J. Clin. Invest. 91, 819-828. doi: 10.1172/JCI116302

De Vries, M. G., Arseneau, L. M., Lawson, M. E., and Beverly, J. L. (2003). Extracellular glucose in rat ventromedial hypothalamus during acute and recurrent hypoglycemia. Diabetes 52, 2767-2773. doi: 10.2337/diabetes.52.11.2767

Diano, S., Horvath, B., Urbanski, H. F., Sotonyi, P., and Horvath, T. L. (2003). Fasting activates the nonhuman primate hypocretin (orexin) system and its postsynaptic targets. Endocrinology 144, 3774-3778. doi: 10.1210/en.2003-0274

Diggs-Andrews, K. A., Zhang, X., Song, Z., Daphna-Iken, D., Routh, V. H., and Fisher, S. J. (2010). Brain insulin action regulates hypothalamic glucose sensing and the counterregulatory response to hypoglycemia. Diabetes 59, 2271-2280. doi: $10.2337 / \mathrm{db} 10-0401$

Donovan, C. M., Hamilton-Wessler, M., Halter, J. B., and Bergman, R. N. (1994). Primacy of liver glucosensors in the sympathetic response to progressive hypoglycemia. Proc. Natl. Acad. Sci. U.S.A. 91, 2863-2867. doi: 10.1073/pnas.91.7.2863

Dunn-Meynell, A. A., Routh, V. H., Kang, L., Gaspers, L., and Levin, B. E. (2002). Glucokinase is the likely mediator of glucosensing in both glucoseexcited and glucose-inhibited central neurons. Diabetes 51, 2056-2065. doi: 10.2337/diabetes.51.7.2056

Dunn-Meynell, A. A., Sanders, N. M., Compton, D., Becker, T. C., Eiki, J. I, Zhang, B. B., et al. (2009). Relationship among brain and blood glucose levels and spontaneous and glucoprivic feeding. J. Neurosci. 29, 7015-7022. doi: 10.1523/JNEUROSCI.0334-09.2009

Elmquist, J. K. (2001). Hypothalamic pathways underlying the endocrine, autonomic, and behavioral effects of leptin. Physiol. Behavior. 74, 703-708. doi: 10.1016/S0031-9384(01)00613-8

Ferenczi, S., Zelei, E., Pintér, B., Szoke, Z., and Kovács, K. J. (2010). Differential regulation of hypothalamic neuropeptide Y hnRNA and mRNA during psychological stress and insulin-induced hypoglycemia. Mol. Cell. Endocrinol. 321, 138-145. doi: 10.1016/j.mce.2010.02.036

Fergani, C., Routly, J. E., Jones, D. N., Pickavance, L. C., Smith, R. F., and Dobson, H. (2014). Kisspeptin, c-Fos and CRFR Type 2 Co-expression in the hypothalamus after insulin-induced hypoglycaemia. Reprod. Domest. Anim. 49, 433-440. doi: 10.1111/rda.12293

Fioramonti, X., Contie, S., Song, Z., Routh, V. H., Lorsignol, A., and Penicaud, L. (2007). Characterization of glucosensing neuron subpopulations in the arcuate nucleus: integration in NPY and POMC networks? Diabetes 56, 1219-1227. doi: $10.2337 / \mathrm{db} 06-0567$

Fioramonti, X., Deak, A., Deshpande, S., Carneiro, L., Zhou, C., Sayed, N., et al. (2013). Hypothalamic S-nitrosylation contributes to the counter-regulatory response impairment following recurrent hypoglycemia. PLoS ONE 8:e68709. doi: 10.1371/journal.pone.0068709

Fioramonti, X., Lorsignol, A., Taupignon, A., and Penicaud, L. (2004). A New ATPSensitive $\mathrm{K}^{+}$channel-independent mechanism is involved in glucose-excited neurons of mouse arcuate nucleus. Diabetes 53, 2767-2775. doi: 10.2337/diabetes.53.11.2767

Fioramonti, X., Marsollier, N., Song, Z., Fakira, K. A., Patel, R. M., Brown, S., et al. (2010a). Ventromedial hypothalamic nitric oxide production is necessary for hypoglycemia detection and counterregulation. Diabetes 59, 519-528. doi: $10.2337 / \mathrm{db} 09-0421$
Fioramonti, X., Song, Z., Vazirani, R. P., Beuve, A., and Routh, V. H. (2010b). Hypothalamic nitric oxide in hypoglycemia detection and counterregulation: a two two edged sword. Antioxid. Redox Signal. 14, 505-517. doi: 10.1089/ars.2010.3331

Garcia, M., Millan, C., Balmaceda-Aguilera, C., Castro, T., Pastor, P., Montecinos, H., et al. (2003). Hypothalamic ependymal-glial cells express the glucose transporter GLUT2, a protein involved in glucose sensing. J. Neurochem. 86, 709-724. doi: 10.1046/j.1471-4159.2003.01892.x

González, J. A., Jensen, L. T., Doyle, S. E., Miranda-Anaya, M., Menaker, M., Fugger, L., et al. (2009). Deletion of TASK1 and TASK3 channels disrupts intrinsic excitability but does not abolish glucose or $\mathrm{pH}$ responses of orexin/hypocretin neurons. Eur. J. Neurosci. 30, 57-64. doi: 10.1111/j.1460-9568.2009.06789.x

Gonzalez, J. A., Jensen, L. T., Fugger, L., and Burdakov, D. (2008). MetabolismIndependent sugar sensing in central orexin neurons. Diabetes 57, 2569-2576. doi: $10.2337 / \mathrm{db} 08-0548$

Griffond, B., Risold, P.-Y., Jacquemard, C., Colard, C., and Fellmann, D. (1999). Insulin-induced hypoglycemia increases preprohypocretin (orexin) mRNA in the rat lateral hypothalamic area. Neurosci. Lett. 262, 77-80. doi: 10.1016/S03043940(98)00976-8

Guillod-Maximin, E., Lorsignol, A., Alquier, T., and Penicaud, L. (2004). Acute intracarotid glucose injection towards the brain induces specific c-fos activation in hypothalamic nuclei: involvement of astrocytes in cerebral glucose-sensing in rats. J. Neuroendocrinol. 16, 464-471. doi: 10.1111/j.1365-2826.2004.01185.x

Harris, G. C., Wimmer, M., and Aston-Jones, G. (2005). A role for lateral hypothalamic orexin neurons in reward seeking. Nature 437, 556-559. doi: 10.1038/nature04071

Hevener, A. L., Bergman, R. N., and Donovan, C. M. (1997). Novel glucosensor for hypoglycemic detection localized to the portal vein. Diabetes 46, 1521-1525. doi: $10.2337 /$ diab.46.9.1521

Ibrahim, N., Bosch, M. A., Smart, J. L., Qiu, J., Rubinstein, M., Ronnekleiv, O. K., et al. (2003). Hypothalamic proopiomelanocortin neurons are glucose responsive and express K(ATP) channels. Endocrinol 144, 1331-1340. doi: 10.1210/en.2002-221033

Joly-Amado, A., Denis, R. G. P., Castel, J., Lacombe, A., Cansell, C., Rouch, C., et al. (2012). Hypothalamic AgRP-neurons control peripheral substrate utilization and nutrient partitioning. $E M B O$ J. 31, 4276-4288. doi: 10.1038/emboj.2012.250

Kang, L., Dunn-Meynell, A. A., Routh, V. H., Gaspers, L. D., Nagata, Y., Nishimura, T., et al. (2006). Glucokinase is a critical regulator of ventromedial hypothalamic neuronal glucosensing. Diabetes 55, 412-420. doi: 10.2337/diabetes.55.02.06.db05-1229

Kang, L., Routh, V. H., Kuzhikandathil, E. V., Gaspers, L., and Levin, B. E. (2004). Physiological and molecular properties of rat hypothalamic ventromedial nucleus glucosensing neurons. Diabetes 53, 559. doi: 10.2337/diabetes. 53.3.549

Kang, L., Sanders, N. M., Dunn-Meynell, A. A., Gaspers, L. D., Routh, V. H., Thomas, A. P., et al. (2008). Prior hypoglycemia enhances glucose responsiveness in some ventromedial hypothalamic glucosensing neurons. Am. J.Physiol. Regul. Integr. Comp. Physiol. 294, R784-R792. doi: 10.1152/ajpregu.00645.2007

Karnani, M. M., Szabó G., Erdélyi, F., and Burdakov, D. (2013). Lateral hypothalamic GAD65 neurons are spontaneously firing and distinct from orexinand melanin-concentrating hormone neurons. J. Physiol. 591, 933-953. doi: 10.1113/jphysiol.2012.243493

Kelley, A. E., Baldo, B. A., and Pratt, W. E. (2005). A proposed hypothalamicthalamic-striatal axis for the integration of energy balance, arousal, and food reward. J. Comp. Neurol. 493, 72-85. doi: 10.1002/cne.20769

Kohno, D., Gao, H. Z., Muroya, S., Kikuyama, S., and Yada, T. (2003). Ghrelin directly interacts with neuropeptide-Y-Containing neurons in the rat arcuate nucleus: $\mathrm{Ca}^{2+}$ signaling via protein kinase a and N-Type channel-dependent mechanisms and cross-talk with leptin and orexin. Diabetes 52, 948-956. doi: 10.2337/diabetes.52.4.948

Kohno, D., Nakata, M., Maekawa, F., Fujiwara, K., Maejima, Y., Kuramochi, M., et al. (2007). Leptin suppresses ghrelin-induced activation of neuropeptide y neurons in the arcuate nucleus via phosphatidylinositol 3-kinase- and phosphodiesterase 3-mediated pathway. Endocrinology 148, 2251-2263. doi: 10.1210/en.2006-1240

Kohno, D., Sone, H., Minokoshi, Y., and Yada, T. (2008). Ghrelin raises $\left[\mathrm{Ca}^{2+}\right]$ i via AMPK in hypothalamic arcuate nucleus NPY neurons. Biochem. Biophys. Res. Commun. 366, 388-392. doi: 10.1016/j.bbrc.2007.11.166 
Langlet, F., Levin Barry, E., Luquet, S., Mazzone, M., Messina, A., Dunn-Meynell Ambrose, A., et al. (2013). Tanycytic VEGF-A boosts blood-hypothalamus barrier plasticity and access of metabolic signals to the arcuate nucleus in response to fasting. Cell Metab. 17, 607-617. doi: 10.1016/j.cmet.2013.03.004

Languren, G., Montiel, T., Julio-Amilpas, A., and Massieu, L. (2013). Neuronal damage and cognitive impairment associated with hypoglycemia: an integrated view. Neurochem. Int. 63, 331-343. doi: 10.1016/j.neuint.2013.06.018

Le Foll, C., Dunn-Meynell, A. A., Miziorko, H. M., and Levin, B. E. (2014). Regulation of hypothalamic neuronal sensing and food intake by ketone bodies and fatty acids. Diabetes 63, 1259-1269. doi: 10.2337/db13-1090

Le Foll, C., Dunn-Meynell, A., Musatov, S., Magnan, C., and Levin, B. E. (2013). FAT/CD36: a major regulator of neuronal fatty acid sensing and energy homeostasis in rats and mice. Diabetes 62, 2709-2716. doi: 10.2337/db12-1689

Leshan, R. L., Greenwald-Yarnell, M., Patterson, C. M., Gonzalez, I. E., and Myers, M. G. (2012). Leptin action through hypothalamic nitric oxide synthase1-expressing neurons controls energy balance. Nat. Med. 18, 820-823. doi: $10.1038 / \mathrm{nm} .2724$

Levin, B. E. (2000). Glucose-regulated dopamine release from substantia nigra neurons. Brain Res. 874, 158-164. doi: 10.1016/S0006-8993(00)02573-7

Levin, B. E. (2002). Metabolic sensors. Viewing glucosensing neurons from a broader perspective. Physiol. Behavior. 76, 397-401. doi: 10.1016/S00319384(02)00763-1

Levin, B. E., Planas, B., Routh, V. H., Hamilton, J., Stern, J. S., and Horwitz, B. A. (1993). Altered alpha 1-adrenoceptor binding in intact and adrenalectomized obese Zucker rats (fa/fa). Brain Res. 614, 146-154. doi: 10.1016/00068993(93)91028-Q

Levin, B. E., Routh, V. H., Kang, L., Sanders, N. M., and Dunn-Meynell, A. A. (2004). Neuronal glucosensing: what do we know after 50 years? Diabetes 53, 2521-2528. doi: 10.2337/diabetes.53.10.2521

Lindberg, D., Chen, P., and Li, C. (2013). Conditional viral tracing reveals that steroidogenic factor 1-positive neurons of the dorsomedial subdivision of the ventromedial hypothalamus project to autonomic centers of the hypothalamus and hindbrain. J. Comp. Neurol. 521, 3167-3190. doi: 10.1002/cne.23338

Lopez-Barneo, J. (2003). Oxygen and glucose sensing by carotid body glomus cells. Curr. Opin. Neurobiol. 13, 493-499. doi: 10.1016/S0959-4388(03)00093-X

López, M., Seoane, L., del Carmen García, M., Lago, F., Casanueva, F. F., Señarís, R., et al. (2000). Leptin regulation of prepro-orexin and orexin receptor mRNA levels in the hypothalamus. Biochem. Biophys. Res. Commun. 269, 41-45. doi: $10.1006 /$ bbrc. 2000.2245

Louis, G. W., Leinninger, G. M., Rhodes, C. J., and Myers, M. G. Jr. (2010). Direct innervation and modulation of orexin neurons by lateral hypothalamic LepRb neurons. J. Neurosci. 30, 11278-11287. doi: 10.1523/JNEUROSCI.1340-10.2010

Lynch, R. M., Tompkins, L. S., Brooks, H. L., Dunn-Meynell, A. A., and Levin, B. E. (2000). Localization of glucokinase gene expression in the rat brain. Diabetes 49, 693-700. doi: 10.2337/diabetes.49.5.693

Maekawa, F., Toyoda, Y., Torii, N., Miwa, I., Thompson, R. C., Foster, D. L., et al. (2000). Localization of glucokinase-like immunoreactivity in the rat lower brain stem: for possible location of brain glucose-sensing mechanisms. Endocrinology 141, 375-384. doi: 10.1210/endo.141.1.7234

Magnuson, M. A. (1990). Glucokinase gene structure. Functional implications of molecular genetic studies. [Review] [31 refs]. Diabetes 39, 523-527. doi: 10.2337/diab.39.5.523

Marsollier, N., Kassis, N., Mezghenna, K., Soty, M., Fioramonti, X., Lacombe, A., et al. (2009). Deregulation of hepatic insulin sensitivity induced by central lipid infusion in rats is mediated by nitric oxide. PLOS ONE 4:e6649. doi: 10.1371/journal.pone.0006649

Marston, O. J., Hurst, P., Evans, M. L., Burdakov, D. I., and Heisler, L. K. (2011). Neuropeptide Y cells represent a distinct glucose-sensing population in the lateral hypothalamus. Endocrinology 152, 4046-4052. doi: 10.1210/en. 2011-1307

Marty, N., Dallaporta, M., Foretz, M., Emery, M., Tarussio, D., Bady, I., et al. (2005). Regulation of glucagon secretion by glucose transporter type 2 (glut2) and astrocyte-dependent glucose sensors. J. Clin. Invest. 115, 3545-3553. doi: 10.1172/JCI26309

Matveyenko, A. V., and Donovan, C. M. (2006). Metabolic sensors mediate hypoglycemic detection at the portal vein. Diabetes 55, 1276-1282. doi: 10.2337/db05-1665

McNay, E. C., Fries, T. M., and Gold, P. E. (2000). Decreases in rat extracellular hippocampal glucose concentration associated with cognitive demand during a spatial task. Proc. Natl. Acad. Sci. U.S.A. 97, 2881-2885. doi: 10.1073/pnas.050583697

McNay, E. C., and Gold, P. E. (1999). Extracellular glucose concentrations in the rat hippocampus measured by zero-net-flux: effects of microdialysis flow rate, strain, and age. J. Neurochem. 72, 785-790. doi: 10.1046/j.14714159.1999.720785.x

McNay, E. C., McCarty, R. C., and Gold, P. E. (2001). Fluctuations in brain glucose concentration during behavioral testing: dissociations between brain areas and between brain and blood. Neurobiol. Learn. Mem. 75, 325-337. doi: 10.1006/nlme.2000.3976

Medeiros, N., Dai, L., and Ferguson, A. V. (2012). Glucose-responsive neurons in the subfornical organ of the rat-a novel site for direct CNS monitoring of circulating glucose. Neuroscience 201, 157-165. doi: 10.1016/j.neuroscience.2011.11.028

Melnick, I. V., Price, C. J., and Colmers, W. F. (2011). Glucosensing in parvocellular neurons of the rat hypothalamic paraventricular nucleus. Eur. J. Neurosci. 34, 272-282. doi: 10.1111/j.1460-9568.2011.07742.x

Migrenne, S., Cruciani-Guglielmacci, C., Kang, L., Wang, R., Rouch, C., Lefevre, A. L., et al. (2006). Fatty acid signaling in the hypothalamus and the neural control of insulin secretion. Diabetes 55, S139-S144. doi: 10.2337/db06-S017

Mizuno, T. M., Makimura, H., Silverstein, J., Roberts, J. L., Lopingco, T., and Mobbs, C. V. (1999). Fasting regulates hypothalamic neuropeptide, Y., agoutirelated peptide, and proopiomelanocortin in diabetic mice independent of changes in leptin or insulin. Endocrinology 140, 4551-4557.

Mobbs, C. V., Kow, L. M., and Yan, X. J. (2001). Brain glucose-sensing mechanisms: ubiquitous silencing by aglycemia vs. hypothalamic neuroendocrine responses. Am. J. Physiol. 281, E649-E654.

Moheet, A., Kumar, A., Eberly, L. E., Kim, J., Roberts, R., and Seaquist, E. R. (2014). Hypoglycemia-Associated autonomic failure in healthy humans: comparison of two vs three periods of hypoglycemia on hypoglycemia-induced counterregulatory and symptom response 5 days later. J. Clin. Endocrinol. Metab. 99, 664-670. doi: 10.1210/jc.2013-3493

Moriguchi, T. S. T., Nambu, T., Yanagisawa, M., and Goto, K. (1999). Neurons containing orexin in the lateral hypothalamic area of the adult rat brain are activated by insulin-induced acute hypoglycemia. Neurosci. Lett. 264, 101-104. doi: 10.1016/S0304-3940(99)00177-9

Mullier, A., Bouret, S. G., Prevot, V., and Dehouck, B. (2009). Differential distribution of tight junction proteins suggests a role for tanycytes in bloodhypothalamus barrier regulation in the adult mouse brain. J. Comp. Neurol. 518, 943-962. doi: 10.1002/cne.22273

Murphy, B. A., Fakira, K. A., Song, Z., Beuve, A., and Routh, V. H. (2009a). AMP-activated Protein Kinase (AMPK) and Nitric Oxide (NO) regulate the glucose sensitivity of ventromedial hypothalamic (VMH) glucose-inhibited (GI) neurons. Am. J. Physiol. Cell Physiol. 297, C750-C758. doi: 10.1152/ajpcell.00127.2009

Murphy, B. A., Fioramonti, X., Jochnowitz, N., Fakira, K., Gagen, K., Contie, S., et al. (2009b). Fasting enhances the response of arcuate neuropeptide Y (NPY)-glucose-inhibited (GI) neurons to decreased extracellular glucose. Am. J. Physiol. Cell Physiol. 296, 746-756. doi: 10.1152/ajpcell. 00641.2008

Nakano, Y., and Oomura, Y. (1986). Feeding-related activity of glucose- and morphine-sensitive neurons in the monkey amygdala. Brain Res. 399, 167-172. doi: 10.1016/0006-8993(86)90613-X

Naufahu, J., Cunliffe, A. D., and Murray, J. F. (2013). The roles of melaninconcentrating hormone in energy balance and reproductive function: are they connected? Reproduction 146, R141-R150. doi: 10.1530/REP-12-0385

Navarro, M., Rodriquez de Fonseca, F., Alvarez, E., Chowen, J. A., Zueco, J. A., Gomez, R., et al. (1996). Colocalization of glucagon-like peptide-1 (GLP-1) receptors, glucose transporter GLUT-2, and glucokinase mRNAs in rat hypothalamic cells: evidence for a role of GLP-1 receptor agonists as an inhibitory signal for food and water intake. J. Neurochem. 67, 1982-1991. doi: 10.1046/j.14714159.1996.67051982.x

Niimi, M., Sato, M., Tamaki, M., Wada, Y., Takahara, J., and Kawanishi, K. (1995). Induction of fos protein in the rat hypothalamus elicited by insulininduced hypoglycemia. Neurosci. Res. 23, 361-364. doi: 10.1016/0168-0102(95) 00965-V

Oomura, Y., Kimura, K., Ooyama, H., Maeo, T., Iki, M., and Kuniyoshi, N. (1964). Reciprocal activities of the ventromedial and lateral hypothalamic area of cats. Science 143, 484-485. doi: 10.1126/science.143.3605.484 
Oomura, Y., Ono, H., Ooyama, H., and Wayner, M. J. (1969). Glucose and osmosensitive neurons of the rat hypothalamus. Nature 222, 282-284. doi: $10.1038 / 222282 \mathrm{a} 0$

Orellana, J. A., Sáez, P. J., Cortés-campos, C., Elizondo, R. J., Shoji, K. F., ContrerasDuarte, S., et al. (2012). Glucose increases intracellular free $\mathrm{Ca}_{2}{ }^{+}$in tanycytes via ATP released through connexin 43 hemichannels. Glia 60, 53-68. doi: 10.1002/glia.21246

Pardal, R., and Lopez-Barneo, J. (2002). Low glucose-sensing cells in the carotid body. Nat. Neurosci. 5, 197-198. doi: 10.1038/nn812

Parton, L. E., Ye, C. P., Coppari, R., Enriori, P. J., Choi, B., Zhang, C. Y., et al. (2007). Glucose sensing by POMC neurons regulates glucose homeostasis and is impaired in obesity. Nature 449, 228-232. doi: 10.1038/nature 06098

Penicaud, L., Leloup, C., Lorsignol, A., Alquier, T., and Guillod, E. (2002). Brain glucose sensing mechanism and glucose homeostasis. Curr. Opin. Clin. Nutr. Metab. Care 5, 539-543. doi: 10.1097/00075197-200209000-00013

Perello, M., Sakata, I., Birnbaum, S., Chuang, J.-C., Osborne-Lawrence, S., Rovinsky, S. A., et al. (2010). Ghrelin increases the rewarding value of highfat diet in an orexin-dependent manner. Biol. Psychiatry 67, 880-886. doi: 10.1016/j.biopsych.2009.10.030

Ramonet, D., Rodriguez, M. J., Pugliese, M., and Mahy, N. (2004). Putative glucosensing property in rat and human activated microglia. Neurobiology Disease 17, 1-9. doi: 10.1016/j.nbd.2003.11.019

Raybould, H. E. (2007). Sensing of glucose in the gastrointestinal tract. Auton. Neurosci. 133, 86-90. doi: 10.1016/j.autneu.2007.01.006

Ritter, S., Li, A.-J., Wang, Q., and Dinh, T. T. (2011). Minireview: the value of looking backward: the essential role of the hindbrain in counterregulatory responses to glucose deficit. Endocrinology 152, 4019-4032. doi: 10.1210/en. 2010-1458

Ritter, S., Llewellyn-Smith, I., and Dinh, T. T. (1998). Subgroups of hindbrain catecholamine neurons are selectively activated by 2-deoxy-D-glucose induced metabolic challenge. Brain Res. 805, 41-54. doi: 10.1016/S0006-8993(98) 00655-6

Rojas, J. M., and Schwartz, M. W. (2014). Control of hepatic glucose metabolism by islet and brain. Diabetes, Obes. Metab. 16, 33-40. doi: 10.1111/dom.12332

Roland, A. V., and Moenter, S. M. (2011). Glucosensing by GnRH Neurons: inhibition by androgens and involvement of AMP-Activated protein kinase. Mol. Endocrinol. 25, 847-858. doi: 10.1210/me.2010-0508

Routh, V. H., Donovan. C. M., and Ritter, S. (2013). Hypoglycemia Detection. Transl. Endocrinol. Metab. 3, 47-87. doi: 10.1210/TEAM.9781936704200.ch2

Routh, V. H., McArdle, J. J., and Levin, B. E. (1997). Phosphorylation modulates the activity of the ATP-sensitive $\mathrm{K}^{+}$channel in the ventromedial hypothalamic nucleus. Brain Res. 778, 107-119. doi: 10.1016/S0006-8993(97)01043-3

Sanders, N. M., Dunn-Meynell, A. A., and Levin, B. E. (2004). Third ventricular alloxan reversibly impairs glucose counterregulatory responses. Diabetes 53 , 1230-1236. doi: 10.2337/diabetes.53.5.1230

Sawchenko, P. E. (1998). Toward a new neurobiology of energy balance, appetite, and obesity: the anatomists weigh in. J. Comp. Neurol. 402, 435-441.

Sayegh, A. I., Covasa, M., and Ritter, R. C. (2004). Intestinal infusions of oleate and glucose activate distinct enteric neurons in the rat. Auton. Neurosci. 115, 54-63. doi: 10.1016/j.autneu.2004.08.006

Sheng, Z., Santiago, A. M., Thomas, M. P., and Routh, V. H. (2014). Metabolic regulation of lateral hypothalamic glucose-inhibited orexin neurons may influence midbrain reward neurocircuitry. Mol. Cell. Neurosci. 62, 30-41. doi: 10.1016/j.mcn.2014.08.001

Shian, L. R., and Lin, M. T. (1991). Insulin acts on the hypothalamic glucosefacilitated neurons to induce hyperglycemia and hyperinsulinemia in the rat. Experientia 47, 942-944. doi: 10.1007/BF01929887

Shiraishi, T., Oomura, Y., Sasaki, K., and Wayner, M. J. (2000). Effects of leptin and orexin-A on food intake and feeding related hypothalamic neurons. Physiol. Behav. 71, 251-261. doi: 10.1016/S0031-9384(00)00341-3

Silver, I. A., and Erecinska, M. (1994). Extracellular glucose concentration in mammalian brain: continuous monitoring of changes during increased neuronal activity and upon limitation in oxygen supply in normo-, hypo-, and hyperglycemic animals. J. Neurosci. 14, 5068-5076.

Song, Z., Levin, B. E., McArdle, J. J., Bakhos, N., and Routh, V. H. (2001). Convergence of pre- and postsynaptic influences on glucosensing neurons in the ventromedial hypothalamic nucleus. Diabetes 50, 2673-2681. doi: 10.2337/diabetes.50.12.2673
Song, Z., and Routh, V. H. (2005). Differential effects of glucose and lactate on glucosensing neurons in the ventromedial hypothalamic nucleus. Diabetes 54, 15-22. doi: 10.2337/diabetes.54.1.15

Song, Z., and Routh, V. H. (2006). Recurrent hypoglycemia reduces the glucose sensitivity of glucose-inhibited neurons in the ventromedial hypothalamus nucleus (VMN). Am. J. Physiol. Regul. Integr. Comp. Physiol. 291, R1283-R1287. doi: 10.1152/ajpregu.00148.2006

Spanswick, D., Smith, M. A., Groppi, V. E., Logan, S. D., and Ashford, M. L. J. (1997). Leptin inhibits hypothalamic neurons by activation of ATP-sensitive potassium channels. Nature 390, 521-525. doi: 10.1038/37379

Spanswick, D., Smith, M. A., Mirshamsi, S., Routh, V. H., and Ashford, M. L. J. (2000). Insulin activates ATP-sensitive $\mathrm{K}^{+}$channels in hypothalamic neurons of lean, but not obese rats. Nat. Neurosci. 3, 757-758. doi: 10.1038/77660

Stanley, S., Domingos Ana, I., Kelly, L., Garfield, A., Damanpour, S., Heisler, L., et al. (2013). Profiling of glucose-sensing neurons reveals that GHRH neurons are activated by hypoglycemia. Cell Metab. 18, 596-607. doi: 10.1016/j.cmet.2013.09.002

Steffens, A. B., Mogenson, G. J., and Stevenson, J. A. (1972). Blood glucose, insulin, and free fatty acids after stimulation and lesions of the hypothalamus. Am. J. Physiol. 222, 1446-1452.

Steffens, A. B., Scheurink, A. J., Luiten, P. G., and Bohus, B. (1988). Hypothalamic food intake regulating areas are involved in the homeostasis of blood glucose and plasma FFA levels. Physiol. Behav. 44, 581-589. doi: 10.1016/00319384(88)90322-8

Sternson, S. M., Shepherd, G. M. G., and Friedman, J. M. (2005). Topographic mapping of $\mathrm{VMH}$ [rarr] arcuate nucleus microcircuits and their reorganization by fasting. Nat. Neurosci. 8, 1356-1363. doi: 10.1038/nn1550

Stolarczyk, E., Guissard, C., Michau, A., Even, P. C., Grosfeld, A., Serradas, P., et al. (2010). Detection of extracellular glucose by GLUT2 contributes to hypothalamic control of food intake. Am. J. Physiol. Endocrinol. Metab. 298, E1078-E1087. doi: 10.1152/ajpendo.00737.2009

Straub, R. H., Cutolo, M., Buttgereit, F., and Pongratz, G. (2010). Energy regulation and neuroendocrine-immune control in chronic inflammatory diseases. J. Intern. Med. 267, 543-560. doi: 10.1111/j.1365-2796.2010.02218.x

Szepietowska, B., Zhu, W., Chan, O., Horblitt, A., Dziura, J., and Sherwin, R. S. (2011). Modulation of $\beta$-Adrenergic receptors in the ventromedial hypothalamus influences counterregulatory responses to hypoglycemia. Diabetes 60 , 3154-3158. doi: 10.2337/db11-0432

Takahashi, K. A., and Cone, R. D. (2005). Fasting induces a large, leptin-dependent increase in the intrinsic action potential frequency of orexigenic arcuate nucleus neuropeptide Y/Agouti-Related protein neurons. Endocrinology 146, 1043-1047. doi: 10.1210/en.2004-1397

Valassi, E., Scacchi, M., and Cavagnini, F. (2014). Neuroendocrine control of food intake. Nutr. Metab. Cardiovasc. Dis. 18, 158-168. doi: 10.1016/j.numecd.2007.06.004

van Dijk, G., Bottone, A. E., Strubbe, J. H., and Steffens, A. B. (1994). Hormonal and metabolic effects of paraventricular hypothalamic administration of neuropeptide Y during rest and feeding. Brain Res. 660, 96-103. doi: 10.1016/00068993(94)90843-5

Vazirani, R. P., Fioramonti, X., and Routh, V. H. (2013). Membrane potential dye imaging of ventromedial hypothalamus neurons from adult mice to study glucose sensing. J. Vis. Exp. 81:e50861. doi: 10.3791/50861

Wang, Q., Liu, C., Uchida, A., Chuang, J.-C., Walker, A., Liu, T., et al. (2014). Arcuate AgRP neurons mediate orexigenic and glucoregulatory actions of ghrelin. Mol. Metab. 3, 64-72. doi: 10.1016/j.molmet.2013.10.001

Wang, R., Cruciani-Guglielmacci, C., Migrenne, S., Magnan, C., Cotero, V. E., and Routh, V. H. (2005). The effects of oleic-acid (OA) on distinct populations of neurons in the hypothalamic arcuate nucleus (ARC) are dependent on extracellular glucose levels. J. Neurophysiol. 55, 1491-1498. doi: 10.1152/jn.00697.2005

Wang, R., Liu, X., Hentges, S. T., Dunn-Meynell, A. A., Levin, B. E., Wang, W., et al. (2004). The regulation of glucose-excited neurons in the hypothalamic arcuate nucleus by glucose and feeding-relevant peptides. Diabetes 53, 1959-1965. doi: 10.2337/diabetes.53.8.1959

Warne, J. P., Varonin, J. M., Nielsen, S. S., Olofsson, L. E., Kaelin, C. B., Chua, S., et al. (2013). Coordinated regulation of hepatic energy stores by leptin and hypothalamic agouti-related protein. J. Neurosci. 33, 11972-11985. doi: 10.1523/JNEUROSCI.0830-13.2013

Watts, A. G., and Sanchez-Watts, G. (2002). Interactions between heterotypic stressors and corticosterone reveal integrative mechanisms for controlling 
corticotropin-releasing hormone gene expression in the rat paraventricular nucleus. J. Neurosci. 22, 6282-6289.

White, J. D. (1993). Neuropeptide Y: a central regulator of energy homeostasis. Reg. Pept. 49, 93-107.

Williams, R. H., Alexopoulos, H., Jensen, L. T., Fugger, L., and Burdakov, D. (2008). Adaptive sugar sensors in hypothalamic feeding circuits. Proc. Natl. Acad. Sci. U.S.A. 105, 11975-11980. doi: 10.1073/pnas.0802687105

Yamanaka, A., Beuckmann, C. T., Willie, J. T., Hara, J., Tsujino, N., Mieda, M., et al. (2003). Hypothalamic orexin neurons regulate arousal according to energy balance in mice. Neuron 38, 701-713. doi: 10.1016/S0896-6273(03)00331-3

Yang, X. J., Kow, L. M., Funabashi, T., and Mobbs, C. V. (1999). Hypothalamic glucose sensor: similarities to and differences from pancreatic beta-cell mechanisms. Diabetes 48, 1763-1772. doi: 10.2337/diabetes.48.9.1763

Yang, Y., Atasoy, D., Su Helen, H., and Sternson Scott, M. (2011). Hunger states switch a flip-flop memory circuit via a synaptic AMPK-dependent positive feedback loop. Cell 146, 992-1003. doi: 10.1016/j.cell.2011.07.039

Zhao, Y. Y., Guo, L., Du, J., and Liu, G. L. (2005). Effects of acute hypoglycemia on the orexin system in rat. Chin. Med. Sci. J. 20, 55-58.

Zheng, H., Patterson, L. M., and Berthoud, H.-R. (2007). Orexin signaling in the ventral tegmental area is required for high-fat appetite induced by opioid stimulation of the nucleus accumbens. J. Neurosci. 27, 11075-11082. doi: 10.1523/JNEUROSCI.3542-07.2007

Zhou, L., Podolsky, N., Sang, Z., Ding, Y., Fan, X., Tong, Q., et al. (2010). The medial amygdalar nucleus: a novel glucose-sensing region that modulates the counterregulatory response to hypoglycemia. Diabetes 59, 2646-2652. doi: 10.2337/db09-0995

Zhu, W., Czyzyk, D., Paranjape, S. A., Zhou, L., Horblitt, A., Szabó, G., et al. (2010). Glucose prevents the fall in ventromedial hypothalamic GABA that is required for full activation of glucose counterregulatory responses during hypoglycemia. Am. J. Physiol. Endocrinol. Metab. 298, E971-E977. doi: 10.1152/ajpendo.00749.2009

Conflict of Interest Statement: The authors declare that the research was conducted in the absence of any commercial or financial relationships that could be construed as a potential conflict of interest.

Received: 31 July 2014; paper pending published: 11 November 2014; accepted: 26 November 2014; published online: 10 December 2014.

Citation: Routh VH, Hao L, Santiago AM, Sheng Z and Zhou C (2014) Hypothalamic glucose sensing: making ends meet. Front. Syst. Neurosci. 8:236. doi: 10.3389/fnsys 2014.00236

This article was submitted to the journal Frontiers in Systems Neuroscience.

Copyright (c) 2014 Routh, Hao, Santiago, Sheng and Zhou. This is an open-access article distributed under the terms of the Creative Commons Attribution License (CC BY). The use, distribution or reproduction in other forums is permitted, provided the original author(s) or licensor are credited and that the original publication in this journal is cited, in accordance with accepted academic practice. No use, distribution or reproduction is permitted which does not comply with these terms. 